\title{
Splenic abscess by Cutibacterium propionicum in poorly controlled type 2 diabetes
}

\author{
Rahin Mahata, ${ }^{1}$ Mandira Chakraborty, ${ }^{2}$ Partha Pratim Chakraborty ำ , \\ Animesh Maiti ${ }^{1}$
}

${ }^{1}$ Endocrinology and Metabolism, Medical College and Hospital Kolkata, Kolkata, West Bengal, India

${ }^{2}$ Microbiology, Medical College and Hospital Kolkata, Kolkata, West Bengal, India

Correspondence to Dr Partha Pratim Chakraborty: docparthapc@yahoo.co.in

Accepted 25 March 2021
Check for updates

(c) BMJ Publishing Group Limited 2021. No commercial re-use. See rights and permissions. Published by BMJ.

\begin{tabular}{l}
\hline To cite: Mahata R, \\
Chakraborty M, \\
Chakraborty PP, et al. BMJ \\
Case Rep 2021;14:e241106. \\
doi:10.1136/bcr-2020- \\
241106 \\
\hline
\end{tabular}

\section{DESCRIPTION}

A 45-year-old farmer presented with intermittent high-grade fever associated with anorexia, dullaching abdominal pain over left upper quadrant and a documented weight loss of around $20 \mathrm{~kg}$ over the preceding 1 year. He had been advised antitubercular therapy 6 months prior to his presentation with us, which he had discontinued after 2 months. Type 2 diabetes had been diagnosed 5 years prior to his presentation and he had been on oral antidiabetic agents since diagnosis. However, his glycaemic control had been unsatisfactory due to non-compliance. He was addicted to alcohol and tobacco smoking. He denied abdominal trauma or intravenous drug abuse. The patient had pallor and tachycardia (pulse rate: $120 / \mathrm{min}$ ) with a supine blood pressure of 118/68 mm Hg. Spleen was soft, tender and palpable $2 \mathrm{~cm}$ below the left costal margin.

Complete blood count revealed polymorphonuclear leucocytosis (total count: $14.8 \times 10^{9} / \mathrm{L}$ ). Multiloculated splenic abscess (figure 1) was subsequently detected on CT scan of the abdomen. Microscopy of the aspirated pus showed plenty of polymorphonuclear cells with long, slender, branching, non-sporing, gram-positive, non-acid fast bacilli (figure 2A,B). Overnight aerobic incubation of the pus in blood agar grew tiny greyishwhite colonies with alpha haemolysis; however, the organism grew better and gave larger colonies when cultured anaerobically for 24 hours. Gram stain from the colonies also documented filamentous bacilli $(0.5-0.8 \mu \mathrm{m} \times 1-5 \mu \mathrm{m})$ of similar morphology, with various degrees of branching. The bacterium was negative for both catalase and oxidase, but fermented glucose, sucrose and maltose; hence, it was identified as Cutibacterium propionicum, a facultative anaerobe. The same organism was also isolated from blood culture, suggesting haematogenous spread of infection. The patient was treated successfully with betalactam-betalactamase combination for 6 months with complete radiological resolution.

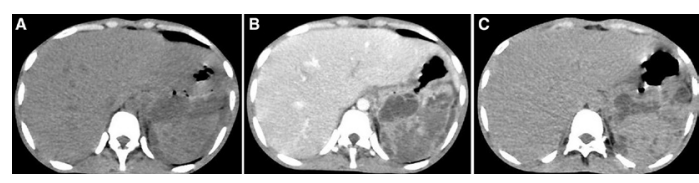

Figure 1 Multiloculated splenic abscess $(9.1 \times 4.3 \times 3.7$ $\mathrm{cm}$ ) on contrast enhanced CT scan of the abdomen: (A) unenhanced, (B) early venous phase (1 min), (C) delayed venous phase (15 min).

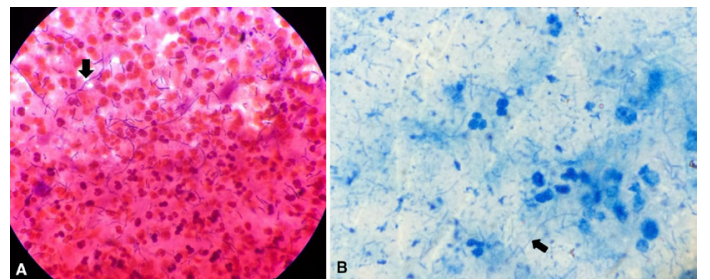

Figure 2 Gram staining of the aspirated pus shows gram-positive branching non-sporing filaments (black arrow) on a background of polymorphonuclear cells (A). The organism was non-acid fast on Ziehl-Neelsen staining (black arrow) (B).

Cutibacterium (formerly known as Propionibacterium) species are pleomorphic, non-spore-forming, gram-positive bacteria with four clinically relevant species: C. acnes, C. avidum, C. granulosum and C. propionicum. ${ }^{1}$ Cutibacterium can tolerate wide fluctuations in oxygen tension and $\mathrm{pH}$. Growth may occur in presence of $100 \%$ oxygen saturation and $\mathrm{pH} 4.5-8.0$, but optimal growth is seen at oxygen tension at or approaching $0 \%$ and at $\mathrm{pH}$ between 5.5 and 6.0. Colonies are very small, smooth and white to grey in colour. C. avidum and C. acnes are skin commensals and have been associated with splenic abscess, when cutaneous integrity is breached following insulin injections. ${ }^{23}$ C. propionicum, the most pathogenic species among Cutibacterium, is

\section{Learning points}

- Splenic abscess due to unusual pathogens is not uncommon in immunocompromised patients. Once gram-positive branching rods are encountered in direct smear or from culture of splenic aspirate, acid-fast staining, biochemical tests and growth characteristics are helpful to narrow down differential diagnoses.

- Cutibacterium propionicum is a gram-positive, non-acid fast, branching bacilli that are facultative anaerobe, form colonies on solid media within 24 hours of aerobic incubation. However, it grows better in anaerobic condition and gives negative result to catalase and oxidase reactions.

- C. acnes phylotype III and Actinomyces israelii are the closest differentials of $C$. propionicum. Unlike $C$. propionicum, $C$. acnes phylotype III is catalase positive, and $A$. israelii has a typical delayed growth pattern. 
Images in...

Table 1 Differential diagnoses of gram-positive branching rods

\begin{tabular}{llll}
\hline Organism & Growth based on $\mathrm{O}_{2}$ requirement & Catalase test & Appearance on Ziehl-Neelsen test (Kinyoun method) \\
\hline Nocardia sp & Aerobic & Positive & Acid fast \\
Rhodococcus sp & Aerobic & Positive & Acid fast \\
Gordonia sp & Aerobic & Positive & Acid fast \\
\hline Tsukamurella sp & Aerobic & Positive & Acid fast \\
Streptomyces sp & Aerobic & Positive & Non-acid fast \\
Actinomadura sp & Aerobic & Positive & Non-acid fast \\
Dermatophilus sp & Aerobic & Positive & Non-acid fast \\
Nocardiopsis sp & Aerobic & Positive & Non-acid fast \\
Thermophilic actinomyces & Aerobic & Positive & Non-acid fast \\
\hline Actinomyces sp & Obligate anaerobe & Positive & Non-acid fast \\
Cutibacterium propionicum & Facultative anaerobe & Negative & Non-acid fast \\
C. acnes phylotype III & Facultative anaerobe & Positive & Non-acid fast \\
A. israelii & Facultative anaerobe & Negative & Non-acid fast \\
\hline
\end{tabular}

known to cause a variety of infections; however, splenic abscess has never been reported. Since the organism resides in human gastrointestinal tract, translocation through gut wall followed by septicaemia probably culminated in seeding of the pathogens in spleen and abscess formation. Altered innate immunity (local and systemic) in diabetes was likely the predisposing factor.

The possible differential diagnoses (DD) have been summarised in table 1 . The closest DD, Actinomyces israelii, starts to grow only after 7-10 days of incubation, while C. propionicum forms colonies within 18-24 hours, and the colony morphologies are also different. ${ }^{4}$

Contributors RM, PPC and AM were involved in management of the patient. MC made the laboratory diagnosis. RM, MC and PPC did the literature search and prepared the manuscript.

Funding The authors have not declared a specific grant for this research from any funding agency in the public, commercial or not-for-profit sectors.
Competing interests None declared.

Patient consent for publication Obtained.

Provenance and peer review Not commissioned; externally peer reviewed.

ORCID iD

Partha Pratim Chakraborty http://orcid.org/0000-0002-3316-4525

\section{REFERENCES}

1 Wade WG. Propionibacterium, Lactobacillus, Actinomyces and other non-spore-forming anaerobic gram-positive rods. In: Murray PR, Baron EJ, Jorgensen JH, et al, eds. Manual of clinical microbiology. 9th ed. Washington DC: ASM Press, 2007: 1. 872-88.

2 Mohammed S, Kollu VS. Rare case of Propionibacterium acnes-related splenic abscess. BMJ Case Rep 2018;2018:bcr-2018-225858.

3 Vohra A, Saiz E, Chan J, et al. Splenic abscess caused by Propionibacterium avidum as a complication of cardiac catheterization. Clin Infect Dis 1998;26:770-1.

4 Wunderink HF, Lashley EELO, van Poelgeest MIE, et al. Pelvic actinomycosis-like disease due to Propionibacterium propionicum after hysteroscopic removal of an intrauterine device. J Clin Microbiol 2011:49:466-8.

Copyright 2021 BMJ Publishing Group. All rights reserved. For permission to reuse any of this content visit

https://www.bmj.com/company/products-services/rights-and-licensing/permissions/

BMJ Case Report Fellows may re-use this article for personal use and teaching without any further permission.

Become a Fellow of BMJ Case Reports today and you can:

- Submit as many cases as you like

- Enjoy fast sympathetic peer review and rapid publication of accepted articles

- Access all the published articles

Re-use any of the published material for personal use and teaching without further permission

Customer Service

If you have any further queries about your subscription, please contact our customer services team on +44 (0) 2071111105 or via email at support@bmj.com.

Visit casereports.bmj.com for more articles like this and to become a Fellow 